\title{
ALTERNATIVE FORMULA FOR RIGID PAVEMENT STRESS CALCULATION IN CORNER LOAD CONDITIONS
}

\section{SAVERIO OLITA*, MAURIZIO DIOMEDI, DONATO CIAMPA

\author{
School of Engineering, University of Basilicata, Potenza, Italy
}

Received 19 May 2020; accepted 29 October 2020

\begin{abstract}
The design of rigid pavements is historically based on the classical Theory of proposed by Westergaard in 1929, which considers the rigid pavement as a thin plate resting on an elastic ground with a Winkler reaction, imposing the congruence of vertical displacements at the points of contact between the pavement structure and the ground. Westergaard's Theory provides expressions for the calculation of maximum stress in concrete slabs for interior, edge and corner load conditions. This work focuses on the development of a Finite Element model, implemented in the ANSYS ${ }^{\circledR}$ environment and calibrated on the basis of the results of the in-scale experimental model developed by Lall and Lees in 1983. The implementation of the FE model was performed through a set of steps capable of reproducing physical and mechanical conditions of the true model, which was further intended to be used for numerical analysis. After the FE model was developed, it was possible to carry out multiple simulations pursuing three main aims: to evaluate the effect of the variation of material properties on the slab stress state, to compare the maximum stresses for the interior and edge load conditions considering Westergaard's Theory,
\end{abstract}

* Corresponding author. E-mail: saverio.olita@unibas.it

Donato CIAMPA (ORCID ID 0000-0002-2575-0049)

Maurizio DIOMEDI (ORCID ID 0000-0002-6550-7449)

Saverio OLITA (ORCID ID 0000-0001-9495-091X)

Copyright (C) 2020 The Author(s). Published by RTU Press

This is an Open Access article distributed under the terms of the Creative Commons Attribution License (http://creativecommons.org/licenses/by/4.0/), which permits unrestricted use, distribution, and reproduction in any medium, provided the original author and source are credited. 
the experimental data and the results of the numerical model, and to use the developed and calibrated model to formulate an alternative mathematical expression, which would allow calculating the stress in corner load conditions.

Keywords: Westergaard solutions, rigid pavements, concrete slab, FE analysis, corner load conditions, stress calculation.

\section{Introduction}

The rigid pavement design is implemented according to calculation settings, which are based on the scheme of a slab resting on the ground and subjected to the action of loads, acting on a limited portion of the slab.

The literature provides solutions for calculating the necessary thickness of the slab by calculating the internal stresses induced by load. In general, in rigid pavements, three methods can be used to determine stresses and strains: mathematical expressions in the closed form (rigorous mathematical formula without empirical approximations); influence diagrams and FE numerical applications (Yoder, \& Witczak, 1975; Huang, 2004; Applied Research Associates, 2004; Agostinacchio, Ciampa, \& Olita, 2016a).

Adequate design of slab thickness is of fundamental importance in minimizing the influence of distresses (e.g. cracking) and ensuring pavement durability (Agostinacchio, Ciampa, Olita, \& Simonetti, 2016b; Pradena, \& Houben, 2018; Yang et al., 2020).

The classical theory par excellence is that of Westergaard (Westergaard, 1926a\&b). It proposes a mathematical formulation which originates from the Lagrange equation for thin plates in conditions of axial symmetry. This theory considers the rigid pavement structure as a thin plate, resting on an elastic ground with a Winkler reaction and imposing the congruence of vertical displacements at the points of contact between the pavement structure and the ground. In its original version, it can only be applied in the presence of a single wheel load of circular, semicircular, elliptic or semi elliptic shape. The influence diagrams developed by Pickett and Ray (1951) can be applied to multiple wheel load conditions of any configuration. Both methods are applicable only to large slabs on a "liquid" foundation. In fact, the supporting ground of the slab is considered a dense liquid or a set of independent "springs", therefore, it is not able to resist shearing stress and lacks any mechanical continuity.

If the load is applied to several slabs on a liquid, solid or generic foundation layer with load being transferred through the joints, it is necessary to use the FE method. 
The Westergaard solution (Westergaard, 1926a\&b) considers three different positions for the load, corresponding to the equivalent load on a single wheel in the case of multiple wheels (Figure 1); in the center or interior, at the edge and at the corner, giving the following relationships:

$$
\begin{gathered}
\sigma_{\text {interior }}=0.275 \cdot(1+v) \cdot \frac{Q}{h^{2}}\left[4 \log _{10}\left(\frac{l}{b}\right)+1.069\right] \\
\sigma_{\text {edge }}=0.529 \cdot(1+0.54 v) \cdot \frac{Q}{h^{2}}\left[4 \log _{10}\left(\frac{l}{b}\right)+0.359\right] \\
\sigma_{\text {corner }}=3 \frac{Q}{h^{2}} \cdot\left[1-\left(\frac{a \sqrt{2}}{l}\right)^{0.6}\right]
\end{gathered}
$$

where:

- $\sigma=$ maximum tensile stress in the slab for bending stress;

- $Q=$ acting load (considered as equivalent load on a single wheel, $\left.Q=p \cdot \pi \cdot a^{2}\right)$

- $l=\sqrt[4]{\frac{E h^{3}}{12\left(1-v^{2}\right) \cdot K}}=$ relative stiffness radius, where:

- $E=$ modulus of elasticity of concrete;

- $h=$ thickness of the concrete slab;

- $\quad v=$ Poisson's ratio of concrete;

- $K=$ modulus of subgrade reaction;

- $a=$ radius of the circular area over which the load is assumed to be uniformly distributed;

- $b=$ equivalent radius:

- $b=\sqrt[4]{1.6 a^{2}+h^{2}}-0.675 h$, per $a<1.724 h$;

- $b=a$, per $a>1.724 h$.

The equivalent radius $b$ was introduced by Westergaard in place of the effective $a$ so as to consider the thicknesses too large compared to the radius of a circular load area, it is in contrast to the hypothesis of a thin plate.

In case of the corner load, Eq. (3) that quantifies stress, unlike the other two, is a formula of semiempirical origin provided in a nonclosed form adopted by Westergaard to overcome some mathematical difficulties.

Since this formula has not found comprehensive experimental confirmation, other authors (Pickett, 1951; Teller, \& Sutherland, 1943; Jeuffroy, 1955) have alternatively proposed different expressions that are always of semiempirical origin, of which the most commonly used are the following:
Alternative Formula for Rigid Pavement Stress Calculation in Corner Load Conditions 


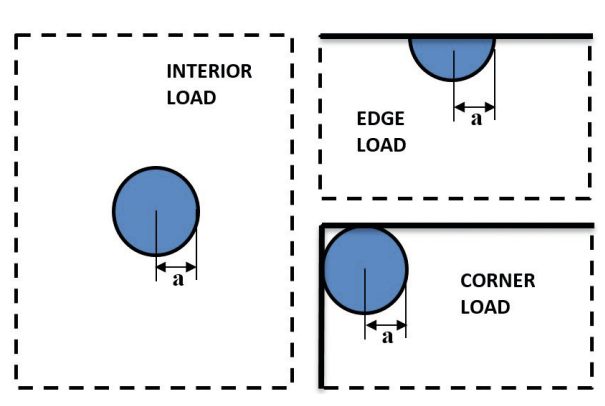

Figure 1. Slab load conditions considered by Westergaard (Westergaard, 1926a\&b)

$$
\begin{gathered}
\sigma=4.2 \frac{Q}{h^{2}}\left[1-\frac{\sqrt{\frac{a}{l}}}{0.925+0.22 \frac{a}{l}}\right] \text { Pickett (Portland Cement Association) } \\
\sigma=3 \frac{Q}{h^{2}}\left[1-\left(\frac{a \sqrt{2}}{l}\right)^{1.2}\right] \text { Teller-Sutherland } \\
\sigma=3.6 \frac{Q}{h^{2}}\left[1-\frac{\sqrt{\frac{a}{l}}}{0.925+0.22 \frac{a}{l}}\right] \text { Jeuffroy }
\end{gathered}
$$

All previous formulas can be considered in the general form:

$$
\sigma=\frac{Q}{h^{2}} C
$$

where coefficient $C$ depends on the position of the load, in addition to the relative stiffness radius $l$ and the size of circular area (radius $a$ ).

It should be remembered that Westergaard (Westergaard, $1926 a \& b)$ completed his work taking into consideration also the case of an elliptical shape area. However, the distinction between elliptical and circular areas does not entail any substantial variation in the determination of the stress state.

Of the three fundamental loading cases investigated by Westergaard, corner loading is undoubtedly the most obscure and debatable. More recently, Ioannides, Thompson, and Baremberg (1985) reconsidered Westergaard's solutions and compared them with finite element analysis 
using ILLI-SLAB finite element software. The finite element results obtained regarding corner deflection are typically about $10 \%$ higher than those predicted by Westergaard. These results were later also confirmed Stress Calculation in Corner Load by other researchers. For example, Zdiri et al. (2009) have demonstrated that for the corner loading case, the FE results were lower in stresses and higher in displacements. Al-Ghafri, \& Javid (2018) have proposed another comparison between manual and computer calculation using KENPAVE software. Maske, Anandkumar, \& Majumder (2013) have performed a sensitivity analysis by varying subgrade soil properties, which confirms that calculation of the corner load may pose difficulties.

The contribution that the authors intend to make is to propose a new mathematical formula for stress calculation by corner load able to overcome the discrepancies between analytical calculations and experimental evidence.

\section{The FE model}

The implemented FE model refers to the in-scale experimentation conducted by Lall and Lees (Lall, 1969; Lall, \& Lees, 1983), it has been calibrated on the basis of these experimental results. The adopted calibration methodology has been developed in three phases: schematization of the slab and verification of the static and dynamic behavior of the implemented model; identification of adequate boundary conditions, suitable for containment of possible negatives boundary effects (dimensioning of a significant volume of the support ground, etc.); comparison of the results obtained through numerical analysis and the experimental measurements recorded. The obtained results show the ability of the developed model to reproduce with good approximation the general response of the system.

The dimensions of the rectangular slab are $L_{1}=1.34 \mathrm{~m}$ (52.8 in) and $L_{2}=2.77 \mathrm{~m}$ (109.2 in) with thicknesses $h$ equal to $2.54 \mathrm{~cm}$ (1.0 in) and $3.38 \mathrm{~cm}$ (1.33 in). According to Westergaard's Theory (slab length larger than or equal to 8 times the relative stiffness radius), such dimensions allow considering the slab of infinite length, when it is loaded in the center, and of semi-infinite length in the case of load at the edge (Figure 2).

The geometry of the FE model, implemented in ANSYS ${ }^{\circledR}$ environment, is defined by the concrete slab described above, embedded in a parallelepiped that constitutes the support ground of such dimensions rendering practically irrelevant edge effects on the slab response. The parallelepiped measures are $2.5 \times 5.0 \times 9.0 \mathrm{~m}$ (Figure 3) . 


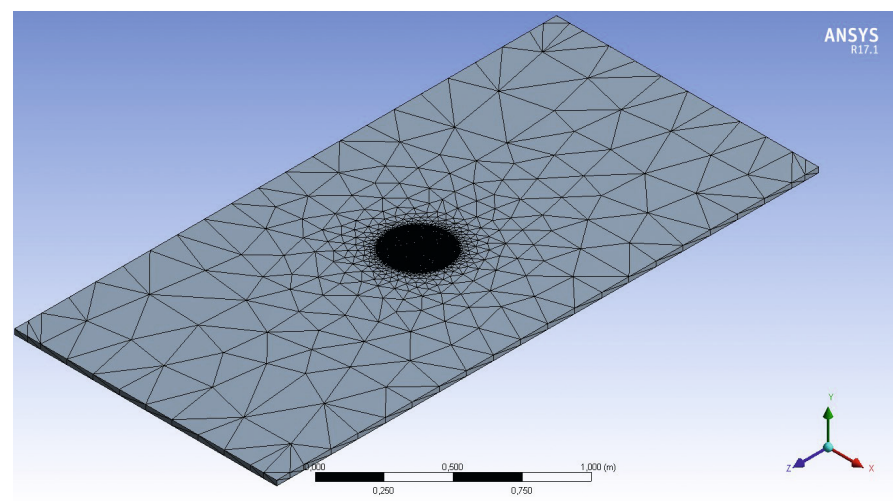

Figure 2. FE model of the slab loaded in the center

The parallelepiped constraint conditions include the fixed support of the base, while lateral surface movements are blocked in the orthogonal directions.

The surfaces in contact between the slab and the ground are bound by a constraint of the bonded type that imposes congruence of displacements.

SOLID187 is the finite element used in 3-D modelling. This element is a higher order 3-D, 10-node element, it demonstrates a quadratic displacement behaviour and is well suited for modelling irregular meshes. The element is defined by 10 nodes having three degrees of freedom at each node: translations in the nodal $\mathrm{x}, \mathrm{y}$ and $\mathrm{z}$ directions. The element has plasticity, hyperelasticity, creep, stress

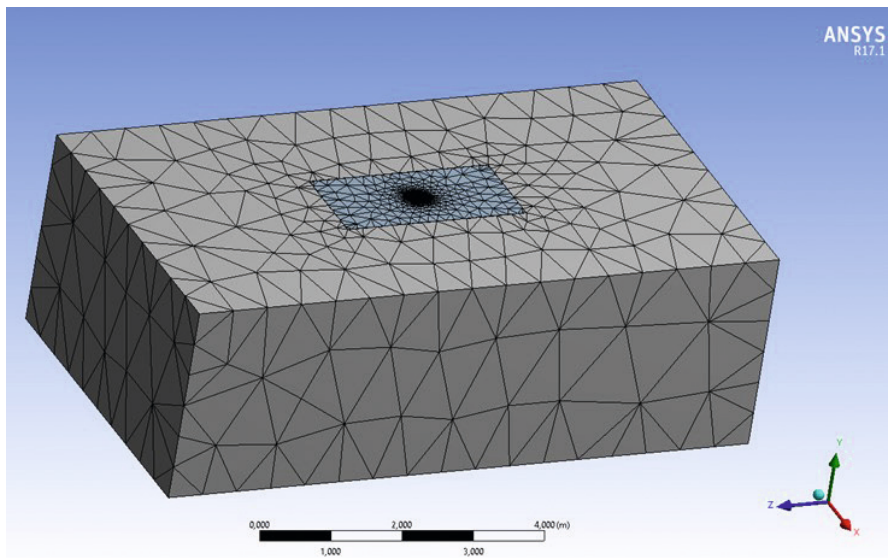

Figure 3. Complete FE model with slab loaded in the center 
stiffening, large deflection, and large strain capabilities. CONTA174 and TARGE170 elements were also used in the modelling of plate-toground contact. The mesh of the model was made using the advanced features provided by ANSYS ${ }^{\circledR}$ software. In particular, the automatic adaptive meshing was used, this is a highly robust meshing technique that produces an efficient mesh for guaranteed accuracy as quickly as possible (ANSYS $\left.{ }^{\circledR}, 2020\right)$.

\section{Influence of material properties on stress analysis}

In the first stage of this study, it was considered appropriate to evaluate the effect of the variability of intrinsic parameters of materials forming the model on the stress state generated by loads. The comparison between Westergaard's and FE solution was carried out for this purpose referring to the only model with load in the center equal to $2.1 \mathrm{kN}$ distributed on a circular shape of radius equal to $3.35 \mathrm{~cm}$ and with slab height equal to $2.54 \mathrm{~cm}$. The maximum stress response was assessed by varying one parameter at a time, maintaining all other parameters constant and equal to the average values set as a reference.

The average parameters of the materials have been set as follows: $E=46540 \mathrm{MPa}, v=0.15$ for concrete and $K=220 \mathrm{MPa} / \mathrm{m}, v=0.45$ for the subgrade.

Variations of the concrete modulus are attributable to the nonhomogeneity of the aggregates and variations of the water-cement ratio. As already noted, the average value of modulus $E$, assumed by Lall and Lees (Lall, 1969; Lall, \& Lees, 1983), is equal to $E=46540 \mathrm{MPa}$.

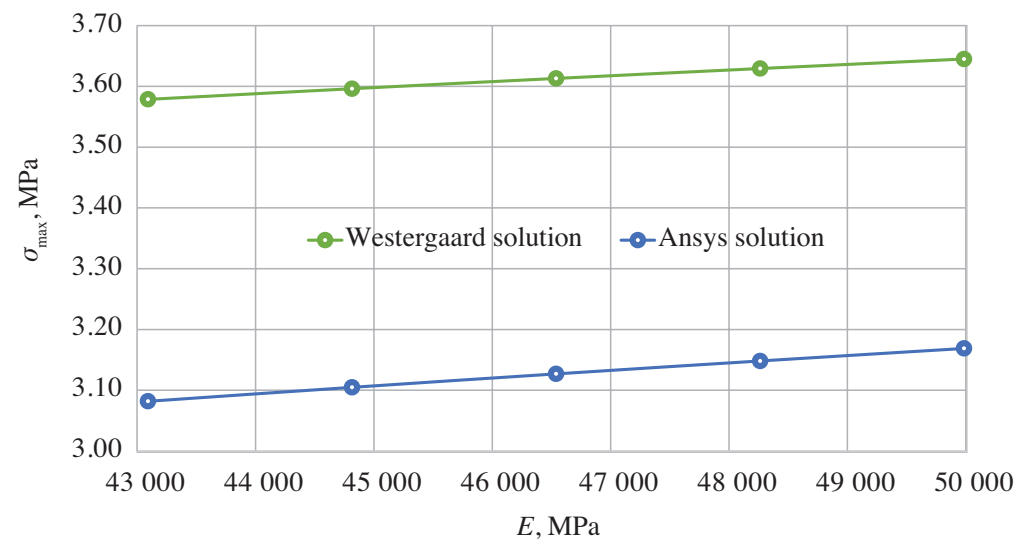

Figure 4. Variation of the concrete modulus
Alternative Formula for Rigid Pavement Stress Calculation in Corner Load Conditions 


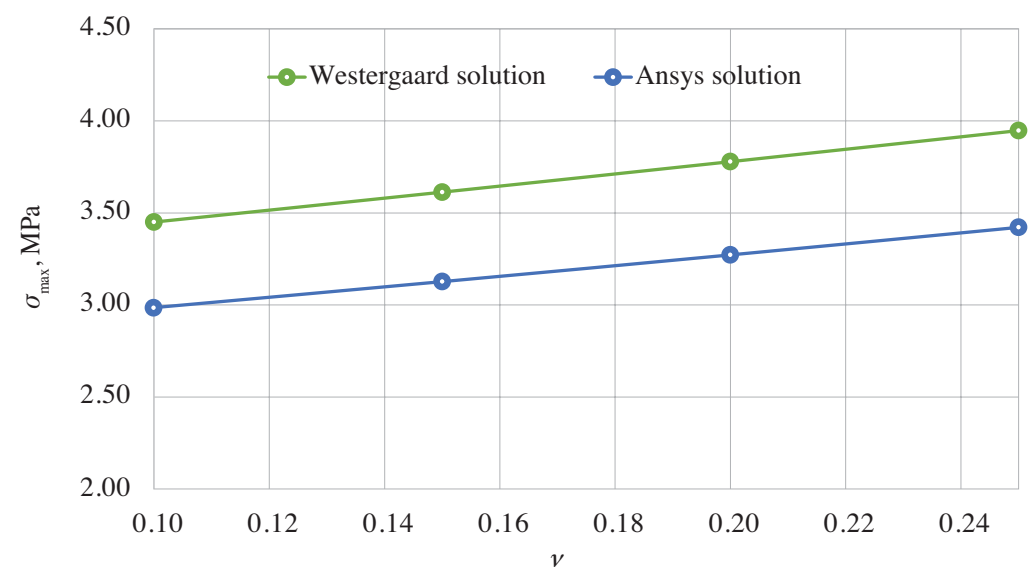

Figure 5. Variation of concrete Poisson's ratio $v$

Therefore, assuming a variability of about $\pm 8 \%$, the range between $43090 \mathrm{MPa}$ and $49985 \mathrm{MPa}$ has been set as a variation range. The effect of variability of $E$ on the maximum tensile stress value for bending is shown in Figure 4. The stress deviation between the two extremes of $E$ is $1.8 \%$ in the case of considering Westergaard's solution and $2.8 \%$ - in the FE model.

The variability of Poisson's ratio of concrete compared to the mean value of 0.15 assumed by Lall and Lees was assessed in the range $0.10-0.25$. Figure 5 presents the results obtained and shows a linear link between Poisson's ratio and the corresponding maximum stress for both Westergaard's and ANSYS ${ }^{\circledR}$ solutions. The percentage variation

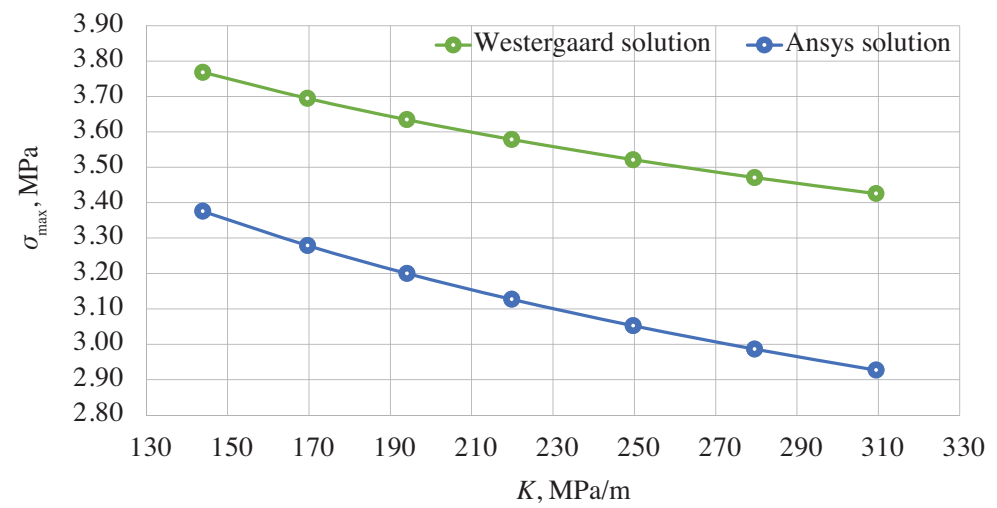

Figure 6. Variation of subgrade reaction modulus $K$ 
between the stress corresponding to the value of $v=0.15$ and $v=0.25$ is approximately $8.5 \%$ in the case of Westergaard's solution and about $8.6 \%$ - in the FE model.

The modulus of subgrade reaction $K$ is the most variable parameter. As known, in real cases it is possible to record deviations of $35 \%$ compared to the expected values. Compared to the average value of $220 \mathrm{MPa} / \mathrm{m}$ set by Lall and Lees, the range of variability considered was $145-310 \mathrm{MPa} / \mathrm{m}$. For the FE stress analysis, it was necessary to give the slab support plane a resilient modulus $\left(M_{\mathrm{R}}\right)$ value (Agostinacchio et al., 2016a), corresponding to the assigned $K$. The AASHTO design Guide (1993) links $K$ and $M_{\mathrm{R}}$ through the relation $K$ $(\mathrm{MPa} / \mathrm{m})=2.028 M_{\mathrm{R}}(\mathrm{MPa})$. However, recent experimental evidence (Ping, \& Sheng, 2011) has proposed the following correlation: $K$ $(\mathrm{MPa} / \mathrm{m})=2.25 M_{\mathrm{R}}(\mathrm{MPa})$, which was adopted in this study. Therefore, the average $M_{R}$ value is equal to $97.80 \mathrm{MPa}$ and the variability range is between 64.50 and $137.80 \mathrm{MPa}$.

Figure 6 shows the trend of the maximum tensile stresses for bending when the subgrade reaction modulus is varying in order to change the corresponding resilient modulus. Stress variation is recorded between the average bearing capacity value and the extreme of the variability interval, equal to $4.30 \%$ for Westergaard's solution and $6.40 \%$ - for the finite element solution.

The subgrade Poisson's ratio is not required by the Westergaard formulation, whereas for the FE model it is necessary to assign a value to it. As known, the values of Poisson's parameter for the subgrade vary from 0.25 to 0.45 with typical value of 0.4 . The numerical analyses were carried out to evaluate the stress variation when parameter $v$ changes,

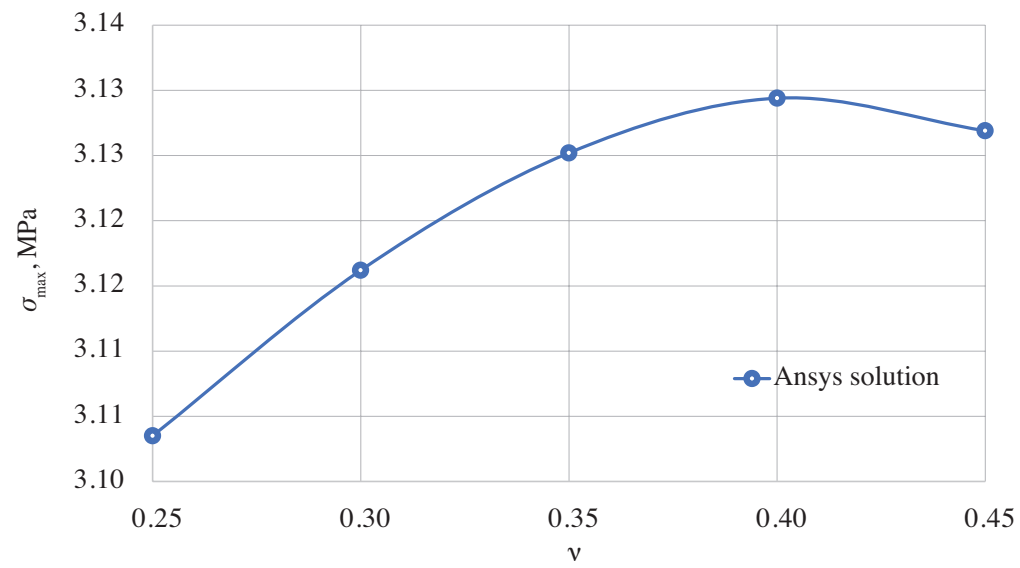

Figure 7. Variation of the subgrade Poisson's ratio
Alternative Formula for Rigid Pavement Stress Calculation in Corner Load Conditions 
Table 1. Maximum variability of maximum tensile stress

\begin{tabular}{|c|c|c|c|c|c|c|}
\hline & \multicolumn{2}{|l|}{ Subgrade } & \multicolumn{2}{|c|}{ Concrete } & \multirow{2}{*}{$\begin{array}{l}\text { Westergaard } \\
\sigma_{\text {max }}, \mathrm{MPa} \\
\end{array}$} & \multirow{2}{*}{$\begin{array}{l}\text { ANSYS }^{\circ} \\
\sigma_{\text {max }}, \mathrm{MPa}\end{array}$} \\
\hline & $K, \mathrm{MPa} / \mathrm{m}$ & $M_{\mathrm{R}}, \mathrm{MPa}$ & $E, \mathrm{MPa}$ & $v$ & & \\
\hline Lower limit & 145 & 64.50 & 43090 & 0.10 & 3.769 & 3.376 \\
\hline Reference value & 220 & 97.80 & 46540 & 0.15 & 3.613 & 3.127 \\
\hline Upper limit & 310 & 137.80 & 49985 & 0.25 & 3.948 & 3.422 \\
\hline \multicolumn{5}{|c|}{ Maximum tensile stress variability, \% } & \pm 9.3 & \pm 9.4 \\
\hline
\end{tabular}

the obtained results are summarized in Figure 7. The stress variation is very modest, in fact, considering the extreme values of the variability range $(0.25-0.45)$, there is a variation of less than $1 \%$. Taking this consideration into account, $v=0.45$ was set in the subsequent analyses.

The maximum variability of maximum tensile stress, compared to the reference values set by both Westergaard's solution and ANSYS ${ }^{\circledR}$, is about 9\%, as shown in Table 1.

\section{Influence of load area radius}

Lall and Lees (Lall, 1969; Lall, \& Lees, 1983) experimentally assessed the maximum tensile stress in the concrete, as the radius of the load area in the in-scale model described in Section 2 was varied. The experimental results are available for two slabs thicknesses $(2.54$ and

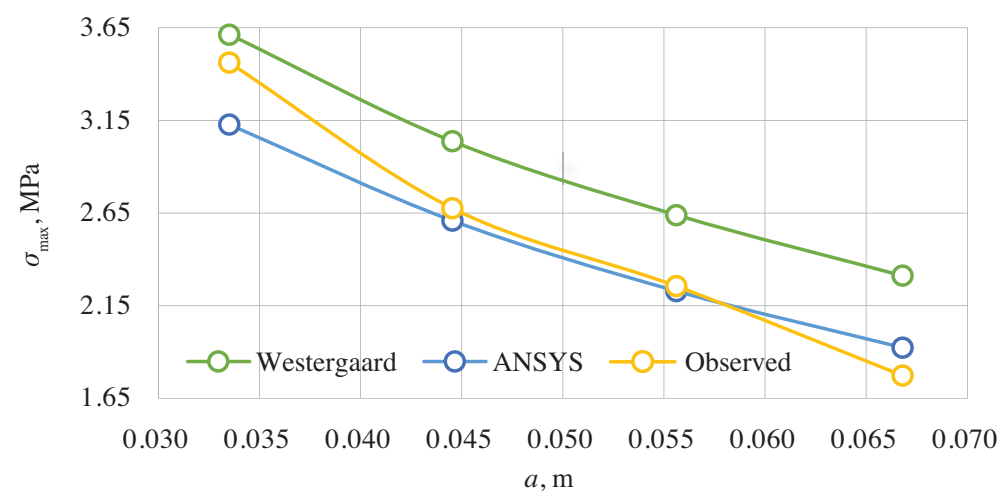

Figure 8. Variation of load area radius ( $h=2.54 \mathrm{~cm}$ and load at the center) 


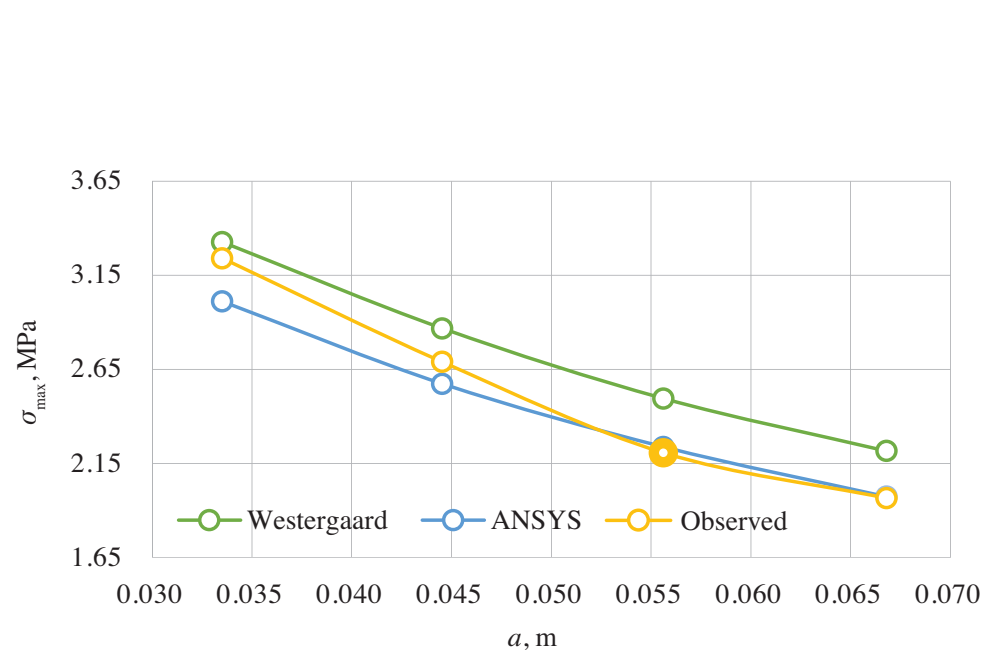

Donato Ciampa,

Maurizio Diomedi,

Saverio Olita

Alternative Formula for Rigid Pavement Stress Calculation in Corner Load Conditions

Figure 9. Variation of load area radius ( $h=3.38 \mathrm{~cm}$ and load at the center)

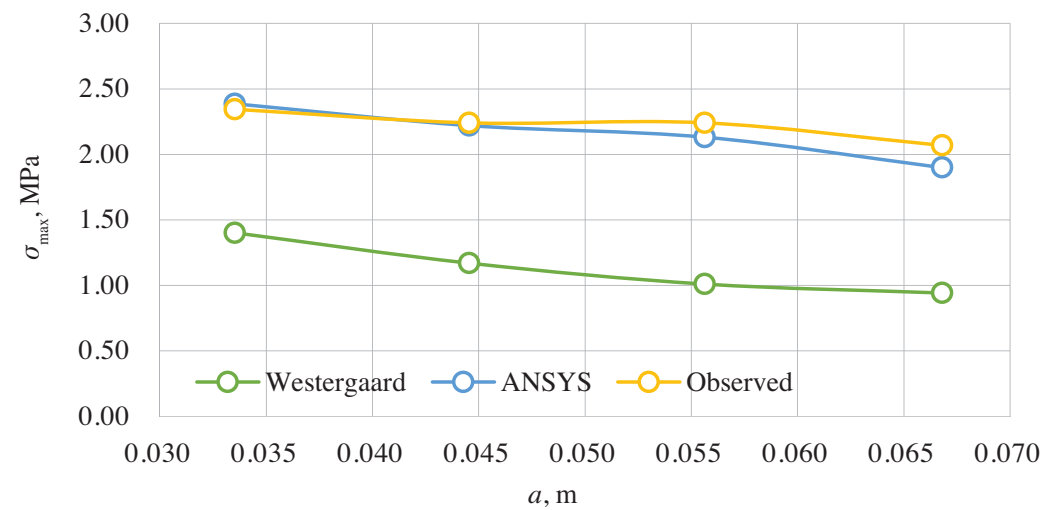

Figure 10. Variation of load area radius $(h=2.54 \mathrm{~cm}$ and load at the edge)

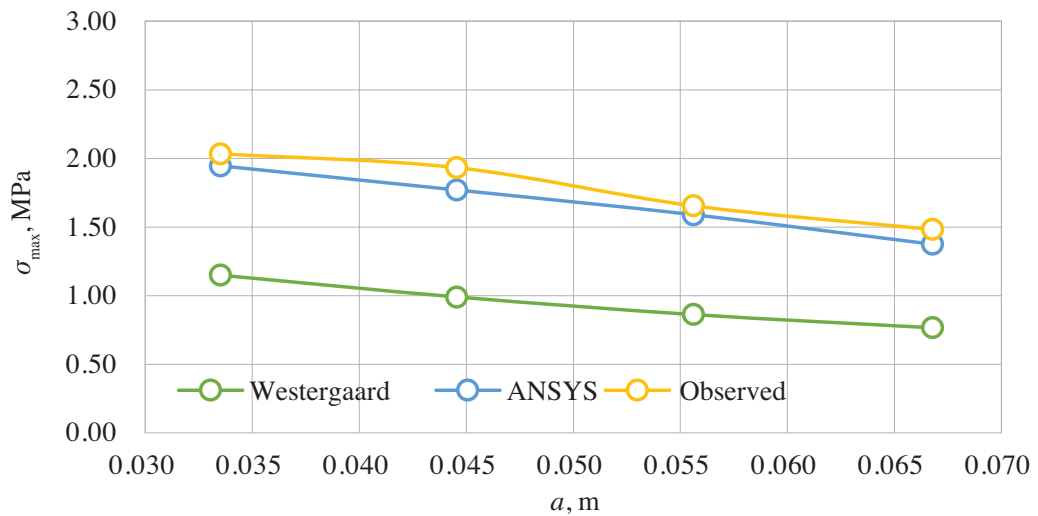

Figure 11. Variation of load area radius $(h=3.38 \mathrm{~cm}$ and load at the edge) 
$3.38 \mathrm{~cm})$, four radii $(3.35,4.45,5.56$ and $6.68 \mathrm{~cm})$ and two load positions (in the center and at the edge) with a load of $2.1 \mathrm{kN}$.

In this study, the experimental results were compared with those obtained by the application of Westergaard's solution and the Finite Element model implemented in ANSYS ${ }^{\circledR}$. Figures 8, 9, 10 and 11 sum up the results obtained and highlight how the experimental observations are best interpreted by the FE model. In particular, a full convergence is achieved between the maximum stress values calculated using the ANSYS $^{\circledR}$ model and the experimental ones for upper slab thicknesses $(h=3.38 \mathrm{~cm})$ and for the load at the edge (Figures 10 and 11).

It is interesting to note that for the load configuration at the edge, unlike load configuration at the center, the maximum stresses provided by the FE model are higher than those calculated by Westergaard and convergent with those experimentally observed.

\section{Load-stress relations}

The next phase of this work was focused on verifying the reliability of the FE model response compared to the experimentally measured values in terms of maximum tensile stress for bending, determined by varying the position (in the center and at the edge), the radius of the load area $(3.35,4.45,5.56 \& 6.68 \mathrm{~cm})$ and the intensity of load $Q(0.45,0.90,1.36$, $1.81 \& 2.26 \mathrm{kN})$ for two slab thicknesses $(2.54 \mathrm{~cm} \& 3.38 \mathrm{~cm})$. The results obtained are summarized in Figures 12 and 13.

The stresses obtained by the ANSYS $^{\circledR}$ model are completely convergent with the experimental observations and, in general, are slightly inferior both in the case of load in the center and load at the edge. However, Westergaard's solution provides stress levels that tend to move away from experimental observations, as the radius of load area increases in the case of load at the center (Figure 12), and are noticeably divergent from the latter in the case of loading at the edge (Figure 13).

In general, the results can be used to detect the fact that when loads are applied to the center of the slab, the maximum stresses detected both by Westergaard and the FE model are representative of the experimentally measured values. Referring to the load condition at the edge, Westergaard's solution loses effectiveness, while the ANSYS $^{\circledR}$ model continues to be congruent with the experimental measurements. 
THE BALTIC JOURNAL

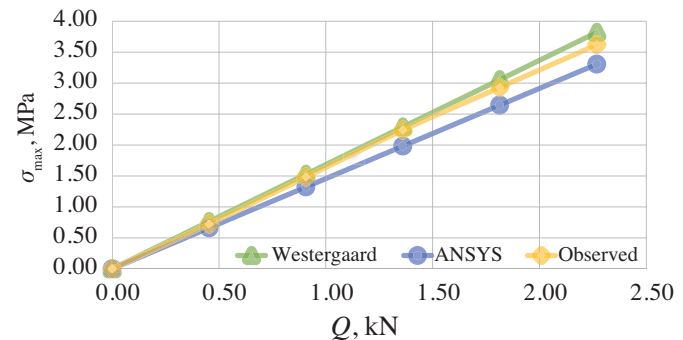

a) $h=2.54 \mathrm{~cm}-a=3.35 \mathrm{~cm}$

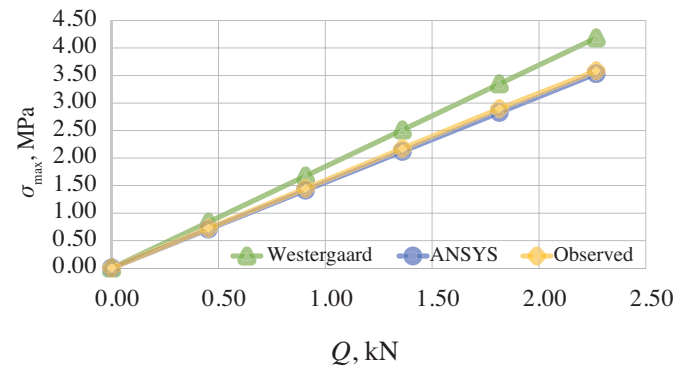

c) $h=2.54 \mathrm{~cm}-a=5.56 \mathrm{~cm}$

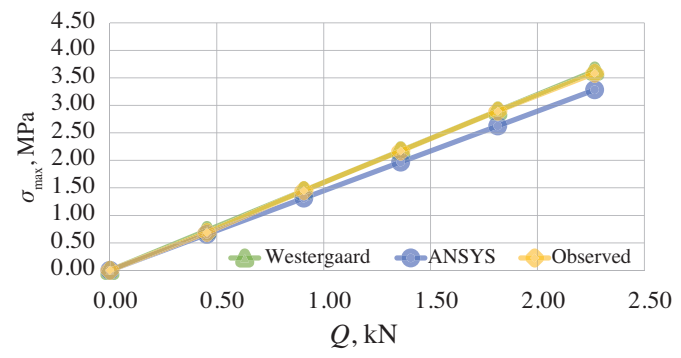

e) $h=3.38 \mathrm{~cm}-a=3.35 \mathrm{~cm}$

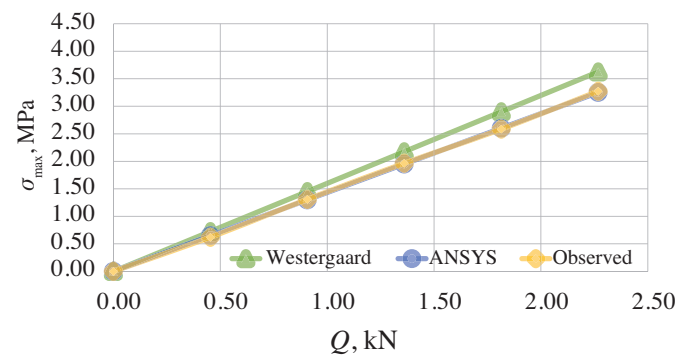

g) $h=3.38 \mathrm{~cm}-a=5.56 \mathrm{~cm}$

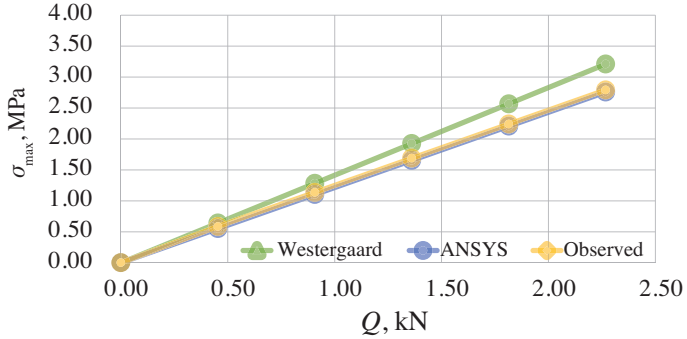

b) $h=2.54 \mathrm{~cm}-a=4.45 \mathrm{~cm}$

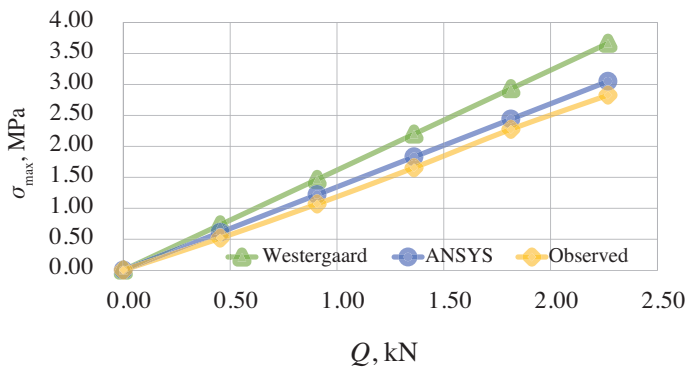

d) $h=2.54 \mathrm{~cm}-a=6.68 \mathrm{~cm}$

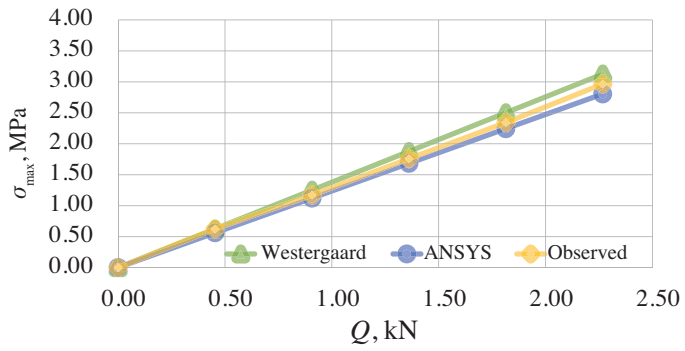

f) $h=3.38 \mathrm{~cm}-a=4.45 \mathrm{~cm}$

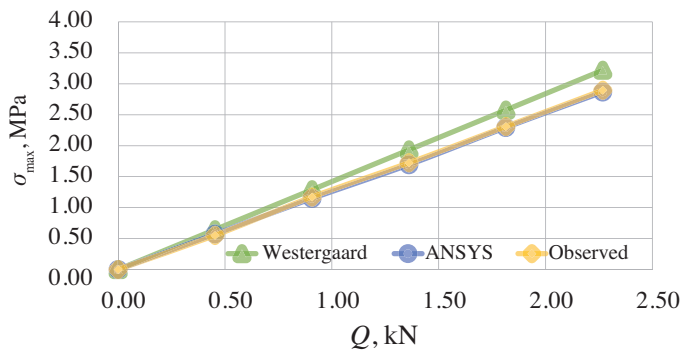

h) $h=3.38 \mathrm{~cm}-a=6.68 \mathrm{~cm}$

Figure 12. Load-stress relations with load in the center 


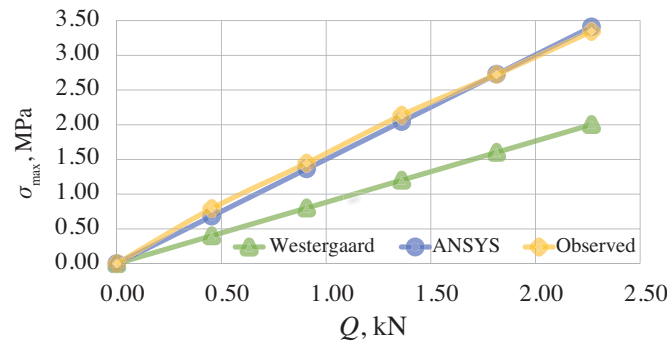

a) $h=2.54 \mathrm{~cm}-a=3.35 \mathrm{~cm}$

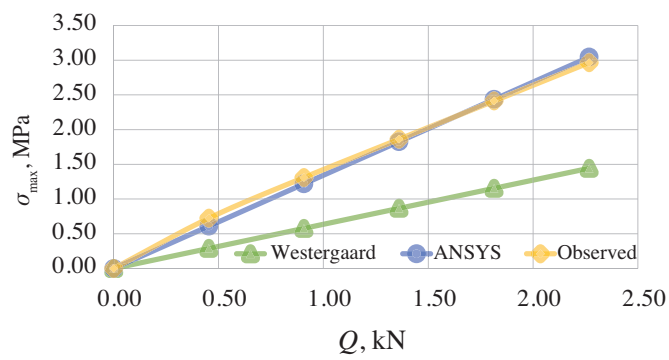

c) $h=2.54 \mathrm{~cm}-a=5.56 \mathrm{~cm}$

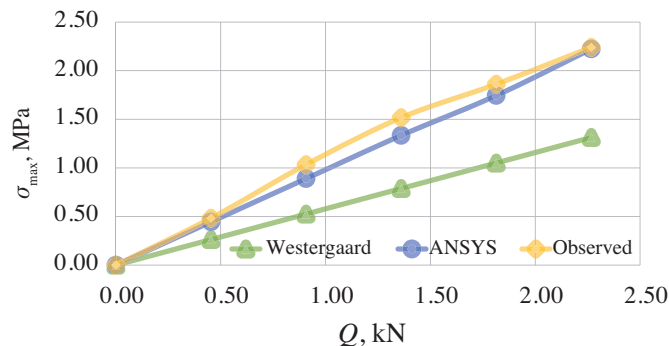

e) $h=3.38 \mathrm{~cm}-a=3.35 \mathrm{~cm}$

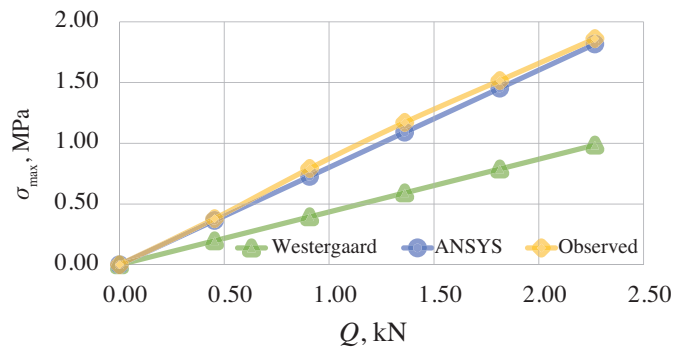

g) $h=3.38 \mathrm{~cm}-a=5.56 \mathrm{~cm}$

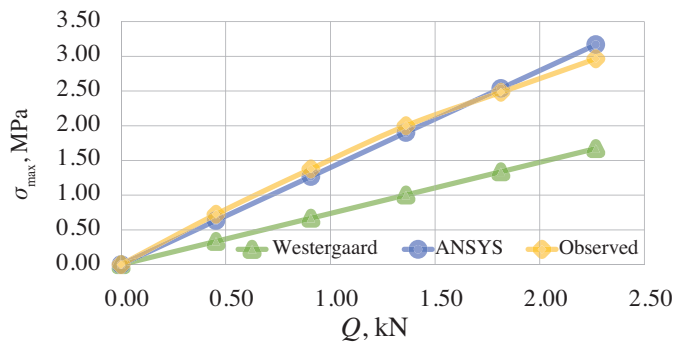

b) $h=2.54 \mathrm{~cm}-a=4.45 \mathrm{~cm}$

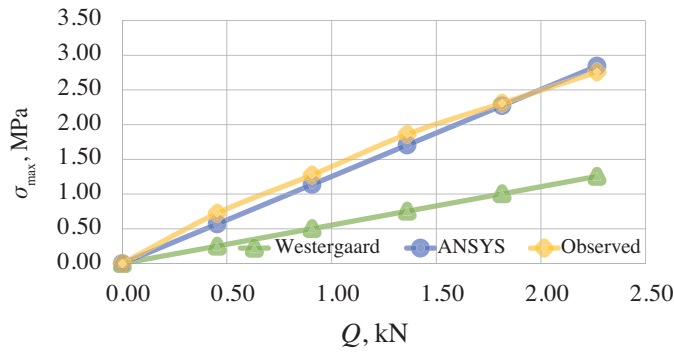

d) $h=2.54 \mathrm{~cm}-a=6.68 \mathrm{~cm}$

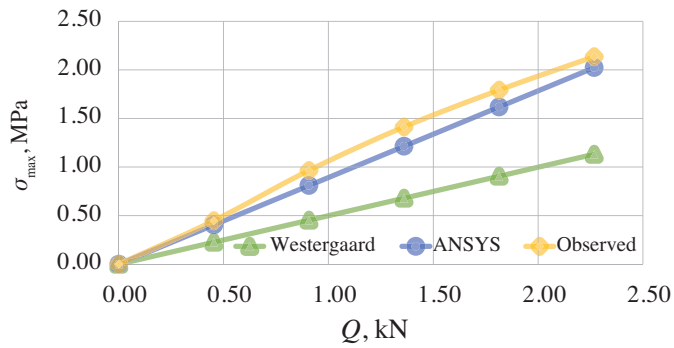

f) $h=3.38 \mathrm{~cm}-a=4.45 \mathrm{~cm}$

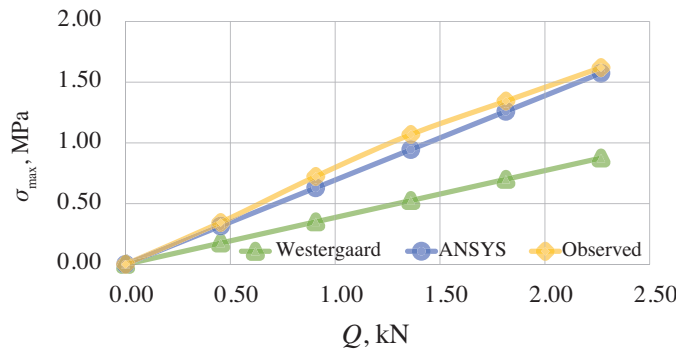

h) $h=3.38 \mathrm{~cm}-a=6.68 \mathrm{~cm}$

Figure 13. Load-stress relations with load at the edge. 


\section{New formulation for corner load conditions}

The Lall and Lees (Lall, 1969; Lall, \& Lees, 1983) experimental data refer only to the conditions of load in the center and at the edge. As known, for the corner load condition, it is relatively complex to derive reliable data from experimental tests, because the major tensile stresses are in the upper part of the slab and at the edge of the circular load area. This is because with the application of the load a "cantilever" type mechanism is developed for both sides of the slab, which naturally generates greater stresses in the upper part of the cantilever and near the constraint.

The difficulty in performing reliable experimental tests and the uncertainty in the evaluation of the maximum slab stresses for the corner load have led numerous authors to the development of alternative semi-empirical expressions, as already highlighted in Section 1.

Moreover, in this load condition, Westergaard's solution does not derive from the strict resolution of the differential equation, but it is a simplified semi-empirical formula adopted by Westergaard to overcome the analytical difficulties that this solution involved.

The most well-known formulations available thanks to Westergaard, Pickett, Teller-Sutherland and Jeuffroy, respectively, which, as highlighted in Section 1, can all be traced back to Eq. (7), where coefficient $C$ depends on the load area radius $a$ and the relative stiffness radius $l$. The dimensionless coefficient $C$ is independent of the ratio $Q / h^{2}$ and can be written as follows:

$$
\begin{gathered}
C=3\left[1-\left(\frac{a \sqrt{2}}{l}\right)^{0.6}\right] \text { Westergaard } \\
C=4.2\left[1-\frac{\sqrt{\frac{a}{l}}}{0.925+0.22 \frac{a}{l}}\right]^{\text {Pickett (Portland Cement Association) }} \\
C=3\left[1-\left(\frac{a \sqrt{2}}{l}\right)^{1.2}\right] \text { Teller-Sutherland } \\
C=3.6\left[1-\frac{\sqrt{\frac{a}{l}}}{0.925+0.22 \frac{a}{l}}\right] \text { Jeuffroy }
\end{gathered}
$$

Alternative Formula for Rigid Pavement Stress Calculation in Corner Load Conditions 
The above study showed how the ANSYS ${ }^{\circledR}$ model provides results in full agreement with the experimental data for the case of load in the center and at the edge, confirming the reliability of the implemented model. Therefore, the authors employed this FE model to study the case of load at the corner and then compared the results obtained with various formulas found in literature.

In order to make such comparison, it is necessary to vary multiple parameters at play for the calculation of the maximum stress and then make the comparison directly with parameter $C$, which can be derived from various formulas. Therefore, countless FE elaborations were necessary to determine coefficient $C$.

The values involved in the variation of parameter $C$ are $a$ and $l$, and in, particular, the ratio $a / l$. In order to have a variation of this ratio, it is necessary to diversify the values of the load radius $a$ and of the stiffness radius $l$ which, in turn, depends on the properties of concrete $(E$ and $v)$, soil properties $\left(K\right.$ or $\left.M_{\mathrm{R}}\right)$ and the thickness of the slab. The basic properties of the starting model are those used for comparative calculations shown in the previous sections. Considering these initial values, many FE analyses were carried out with the load at the corner, from time to time achieving the maximum tensile stress for bending in the concrete.

Four different radius values of the load area $(3.35,4.45,5.56$ and $6.68 \mathrm{~cm}$ ) have been considered, varying $E, v, K$ and $h$ for each load condition, so that at the variation of each individual parameter, the others assume the initial mean values, and then the value taken by parameter $C$ is determined. The variability of parameters $E, v, K$ is the same as the cases examined above, as well as the slab heights considered.

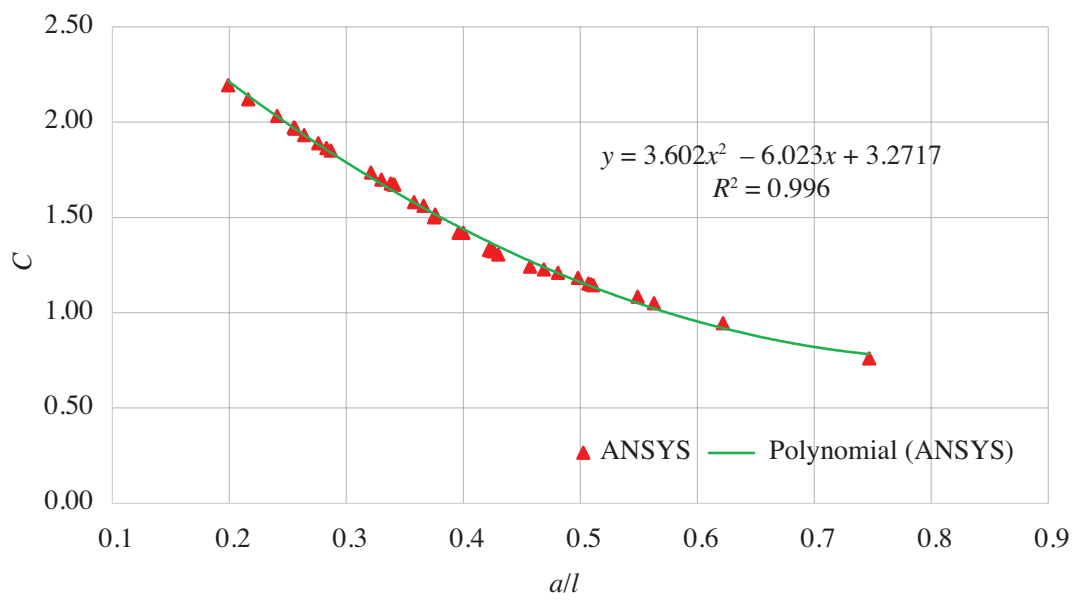

Figure 14. Interpolating curve of C values 
Table 2. C values obtained varying the ratio $a / l$

\begin{tabular}{|c|c|c|c|c|c|}
\hline \multirow{2}{*}{$a / l$} & \multicolumn{5}{|c|}{ Coefficient C } \\
\hline & Westergaard & Pickett & Teller-Sutherland & Jeuffroy & ANSYS $^{\circ}$ \\
\hline 0.199 & 1.599 & 2.268 & 2.346 & 1.944 & 2.194 \\
\hline 0.216 & 1.529 & 2.194 & 2.278 & 1.881 & 2.120 \\
\hline 0.241 & 1.426 & 2.090 & 2.174 & 1.792 & 2.033 \\
\hline 0.255 & 1.375 & 2.040 & 2.120 & 1.749 & 1.972 \\
\hline 0.256 & 1.371 & 2.036 & 2.115 & 1.745 & 1.969 \\
\hline 0.256 & 1.367 & 2.033 & 2.112 & 1.742 & 1.966 \\
\hline 0.264 & 1.339 & 2.005 & 2.080 & 1.719 & 1.933 \\
\hline 0.276 & 1.296 & 1.963 & 2.032 & 1.683 & 1.889 \\
\hline 0.283 & 1.269 & 1.938 & 2.002 & 1.661 & 1.864 \\
\hline 0.287 & 1.255 & 1.924 & 1.985 & 1.650 & 1.851 \\
\hline 0.321 & 1.133 & 1.811 & 1.838 & 1.552 & 1.736 \\
\hline 0.330 & 1.102 & 1.783 & 1.800 & 1.528 & 1.699 \\
\hline 0.338 & 1.073 & 1.756 & 1.762 & 1.505 & 1.678 \\
\hline 0.340 & 1.067 & 1.751 & 1.755 & 1.501 & 1.674 \\
\hline 0.341 & 1.064 & 1.748 & 1.750 & 1.498 & 1.672 \\
\hline 0.358 & 1.007 & 1.697 & 1.675 & 1.455 & 1.581 \\
\hline 0.366 & 0.979 & 1.672 & 1.638 & 1.434 & 1.561 \\
\hline 0.375 & 0.949 & 1.647 & 1.598 & 1.412 & 1.501 \\
\hline 0.376 & 0.948 & 1.645 & 1.596 & 1.410 & 1.516 \\
\hline 0.396 & 0.882 & 1.589 & 1.505 & 1.362 & 1.419 \\
\hline 0.400 & 0.867 & 1.577 & 1.484 & 1.351 & 1.419 \\
\hline 0.422 & 0.798 & 1.519 & 1.384 & 1.302 & 1.330 \\
\hline 0.424 & 0.792 & 1.514 & 1.375 & 1.298 & 1.327 \\
\hline 0.426 & 0.788 & 1.510 & 1.369 & 1.295 & 1.322 \\
\hline 0.430 & 0.775 & 1.500 & 1.350 & 1.285 & 1.306 \\
\hline 0.457 & 0.690 & 1.431 & 1.222 & 1.226 & 1.243 \\
\hline 0.469 & 0.655 & 1.403 & 1.167 & 1.202 & 1.228 \\
\hline 0.481 & 0.620 & 1.374 & 1.111 & 1.178 & 1.210 \\
\hline 0.498 & 0.568 & 1.334 & 1.029 & 1.144 & 1.183 \\
\hline 0.507 & 0.542 & 1.315 & 0.987 & 1.127 & 1.153 \\
\hline 0.509 & 0.536 & 1.309 & 0.976 & 1.122 & 1.149 \\
\hline 0.511 & 0.531 & 1.306 & 0.968 & 1.119 & 1.145 \\
\hline 0.549 & 0.422 & 1.224 & 0.785 & 1.049 & 1.084 \\
\hline 0.563 & 0.383 & 1.195 & 0.717 & 1.024 & 1.050 \\
\hline 0.622 & 0.222 & 1.080 & 0.427 & 0.926 & 0.945 \\
\hline 0.747 & -0.101 & 0.867 & -0.205 & 0.743 & 0.760 \\
\hline
\end{tabular}


By elaborating the results of all conducted FE analyses, it was possible to define 36 values of the $a / l$ ratio and calculate as many values for parameter $C$. Then, for the same parameter combinations, the values of $C$ were calculated by applying equations (8), (9), (10) and (11) found in literature, obtaining the results shown in Table 2.

With $C$ values determined on the basis of the $\mathrm{FE}$ analysis, an interpolating relation of numerical values was sought for. Figure 14 shows the second-degree polynomial regression curve that interpolates these values.

The determinate relation is then:

$$
C=3.6\left(\frac{a}{l}\right)^{2}-6.0\left(\frac{a}{l}\right)+3.3
$$

that allows the authors to propose a new formulation for the determination of the maximum tensile stress due to the load configuration at the corner:

$$
\sigma=3 \frac{Q}{h^{2}}\left[1.2\left(\frac{a}{l}\right)^{2}-2\left(\frac{a}{l}\right)+1.1\right]
$$

Figure 15 shows the pattern of parameter $C$ (which coincides with the trend of stresses minus the ratio $Q / h^{2}$ ) of the new solution proposed in addition to those found in literature. It is noted that the proposed formula is positioned between Pickett and Jeuffroy curves with a gradient of variability, which is very similar to the Westergaard curve that decreases more rapidly as the ratio $a / l$ increases.

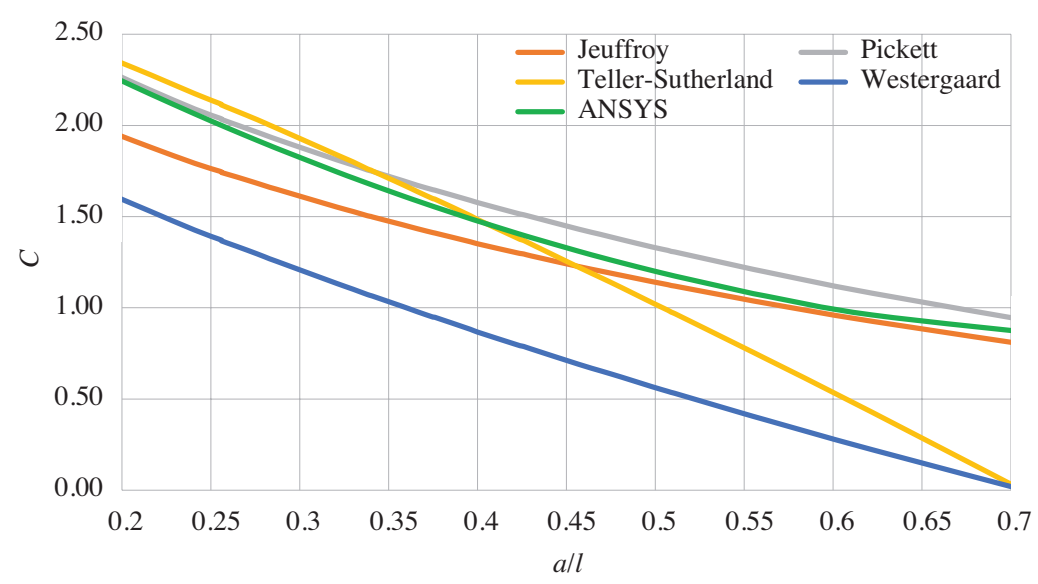

Figure 15. $\mathrm{C}$ values within different theories as a function of $a / /$ ratio 


\section{Conclusions}

The paper focused on the identification of a new mathematical formula for the rigid pavement stress calculation under corner loading conditions able to overcome the limitations of the one initially provided by Westergaard and later by several other authors (Pickett, TellerSutherland, Jeuffroy, etc.).

The result was achieved by implementing a Finite Element model built in the ANSYS ${ }^{\circledR}$ environment capable of evaluating the maximum tensile stress for bending in concrete slabs for all load conditions. The FE model was calibrated with the experimental in-scale model data developed by Lall and Lees and gave results fully convergent with the experimental evidence.

The reliability of the Finite Element solution has been evaluated in function of the variation of the concrete properties, as a function of the subgrade bearing capacity and the load position change, the radius of the circular area over which the load acts, etc. All analyses conducted have confirmed reliability of the ANSYS ${ }^{\circledR}$ model and its ability to represent the investigated physical reality.

By using the FE model, it has been possible to identify a mathematical formula alternative to those currently present in the literature, which is fully convergent with the experimental evidence and therefore able to provide an evaluation of the maximum tensile stress per load at the corner most adherent to reality. The result obtained may be of great use in design of rigid pavements also considering the fact that for the corner load condition, it is relatively difficult to obtain reliable experimental data because the maximum tensile stress develops in the upper part of the slab and at the sides of the circular load contact area due to the establishment of a "cantilever" type mechanism.

\section{REFERENCES}

AASHTO (1993). Guide for design of pavement structures. American Association of State Highway and Transportation Officials. Washington, DC, USA.

Agostinacchio, M., Ciampa, D., \& Olita, S. (2016a). Performance Assessment of JPCP and CRCP Rigid Pavements Implementing M-E Analysis. In: Chabot A., Buttlar W., Dave E., Petit C., Tebaldi G. (eds) 8th RILEM International Conference on Mechanisms of Cracking and Debonding in Pavements. RILEM Bookseries, vol 13. Springer, Dordrecht, pp. 417-423. https://doi.org/10.1007/978-94-024-0867-6_58

Agostinacchio, M., Ciampa, D., Olita, S., \& Simonetti, M. (2016b). The use of steel mesh reinforcement for the cracking control in flexible pavements: FE analysis in static and dynamic conditions. Functional Pavement Design. In
Alternative Formula for Rigid Pavement Stress Calculation in Corner Load Conditions 
Proceedings of the 4th Chinese-European Workshop on Functional Pavement Design, $4^{\text {th }}$ CEW 2016, Delft, The Netherlands, pp. 229-238.

https://doi.org/10.1201/9781315643274-25

Al-Ghafri, I. H. H., \& Javid, M. A. (2018). Comparative analysis of rigid pavement using Westergaard method and computer program. Journal of Soft Computing in Civil Engineering, 2(2), 19-30.

https://doi.org/10.22115/scce.2018.110910.1040

ANSYS ${ }^{\circledR}$ References manual (2020). Retrieved from https://www.ansys.com/

Applied Research Associates Inc. (ARA) \& ERES Consultants Division (2004). Guide for mechanistic-empirical design of new and rehabilitated pavement structures. Final Rep., NCHRP Project 1-37A.0.

Huang, Y. H. (2004). Pavement analysis and design (second edition). Pearson Prentice Hall, USA.

Ioannides, A. M., Thompson, M. R., \& Baremberg, E. J. (1985). Westergaard solutions reconsidered. In TRB No 1043. Washington, DC: Transportation Research Board. Retrieved from http://onlinepubs.trb.org/Onlinepubs/ trr/1985/1043/1043-003.pdf

Jeuffroy, G. (1955). Considerations theoriques sur le calcul des chaussées en béton. Revue Générale Routes et Aérodromes.

Lall, B. (1969). Concrete overlay of concrete pavement. Dissertation, University of Birmingham, Edgbaston, United Kingdom.

Lall, B., \& Lees, G. (1983). Analysis of stresses in overlay-pavement-earth systems. Proceedings of the $62^{\text {nd }}$ Annual Meeting of the Transportation Research Board (Washington D.C.).

Maske, N. A., Anandkumar, A., \& Majumder, A. (2013). Analysis of rigid pavement stresses by finite element method \& Westergaard's method by varying sub-grade soil properties. International Journal of Engineering Science Invention, 2(3). Retrieved from https://pdfs.semanticscholar.org/e29e/5da4d9e0cff9ad53701589ec93bfdbbf4ffe.pdf

Pickett, G. (1951). A study of stresses in the corner of concrete pavement slabs under large corner loads. Chicago: Portland Cement Association.

Pickett, G., \& Ray, G. K. (1951). Influence charts for concrete pavement. Transaction, ASCE, 116, 49-73.

Ping, W. V., \& Sheng, B. (2011). Developing correlation relationship between modulus of subgrade reaction and resilient modulus for Florida subgrade soils. Transportation Research Record, 2232(1), 95-107. https://doi.org/10.3141/2232-10

Pradena, M., \& Houben, L. (2018). Load transfer-crack width relation of non-dowelled jointed plain concrete short slabs. The Baltic Journal of Road and Bridge Engineering, 13(1), 40-45.

https://doi.org/10.3846/bjrbe.2018.388

Teller, L. W., \& Sutherland, E. C. (1943). The structural design of concrete pavements: part 5- an experimental study of the Westergaard analysis of stress conditions in concrete pavement slabs of uniform thickness. Public Roads, 23(8), 167-212.

Westergaard, H. M. (1926). Analysis of stresses in concrete pavement due to variations of temperature. Highway Research Board, 6, 201-215. 
Westergaard, H. M. (1926). Stresses in concrete pavements by theoretical analysis. Public Roads, 7, 25-35.

Yang, S., Zhang, Y., Kaya, O., Ceylan, H., \& Kim, S. (2020). Investigation of longitudinal cracking in widened concrete pavements. The Baltic Journal of Road and Bridge Engineering, 15(1), 211-231. https://doi.org/10.7250/bjrbe.2020-15.468

Yoder, E. J., \& Witczak, M. W. (1975). Principles of pavement design (second edition). John Wiley \& sons Inc., New York, USA.

Zdiri, M., Abriak, N.-E., Ben Ouezdou, M., Loulizi, A., \& Neji, J. (2009). Numerical modelling of a roller compacted concrete pavement under vehicular loading. International Journal of Pavement Research and Technology, 2(5), 188-195. Retrieved from https://www.researchgate.net/publication/266796106_ Numerical_modeling_of_a_roller_compacted_concrete_pavement_under_ vehicular_loading
Alternative Formula for Rigid Pavement Stress Calculation in Corner Load Conditions 